\title{
El turismo alternativo en la Reserva de la Biosfera El Pinacate y Gran Desierto de Altar, Sonora, México
}

DOI: $10.22403 /$ UQROOMX/TYP08/04

\author{
María Reyes Llamas Paz \\ Centro de Estudios Superiores del Estado de Sonora \\ Unidad Académica Sede San Luis Río Colorado
}

RESUMEN

Puerto Peñasco, ubicado al noroeste del estado de Sonora, ha adquirido gran importancia en las últimas décadas por la diversificación de las actividades económicas, destacando el turismo y aquellas actividades indirectas que de él se derivan. El municipio cuenta con una gran cantidad de atractivos turísticos, entre ellos la Reserva de la Biosfera El Pinacate y Gran Desierto deAltar, área natural protegida que cuenta con un gran potencial turístico, cultural y natural susceptible de ser aprovechado de manera racional. El turismo alternativo se encamina al máximo aprovechamiento del patrimonio turístico donde se adquiera un compromiso de integración y respeto con el medio ambiente natural y cultural con la finalidad de generar un desarrollo integrador en términos sociales, sostenibles y ambientales. El capital humano inmerso en los diversos sectores productivos y en la sociedad muestra un gran interés por incorporarse a las actividades turísticas que contribuyan al desarrollo del turismo alternativo en la localidad. Asimismo, en el municipio se cuenta con un mercado potencial nacional y extranjero que contribuirá de forma importante a vincular el desarrollo del turismo alternativo armónica y racionalmente; al crecimiento económico a través de la generación de empleos, la captación de divisas y la diversificación de actividades turísticas; y, como consecuencia, a elevar el bienestar social de los pobladores.

Palabras |Desarrollo sustentable, turismo, turismo alternativo, Puerto

CLAVE Peñasco, Reserva de la Biosfera

Correo electrónico: Ilamasmary@yahoo.com.mx 
El turismo alternativo en la

Reserva de la Biosfera El Pinacate

y Gran Desierto de Altar, Sonora,

México

\section{Introducción}

El presente trabajo tiene como objetivo estudiar la Reserva de la Biosfera El Pinacate y Gran Desierto de Altar como apoyo-atractivo para articular su potencial turístico al turismo alternativo en Puerto Peñasco, Sonora.

La dinámica que presenta el turismo en Puerto Peñasco por medio de las inversiones turísticas, el flujo de visitantes, los recursos humanos especializados en turismo y la industria de la construcción que ha arribado al puerto, ha favorecido al crecimiento y desarrollo de la ciudad. Además del gran impulso recibido por los tres niveles de gobierno, inversionistas, prestadores de servicios, instituciones públicas y privadas han unido esfuerzos para la promoción y desarrollo de la actividad turística en la localidad.

La afluencia turística, sobre todo el turismo extranjero, ha incrementado considerablemente en los últimos años. Para el 2000 arribaron al destino I I 40932 turistas, de los cuales $26.32 \%$ son nacionales y $73.68 \%$ extranjeros. En 2007, la afluencia turística incrementó a 2352482 turistas, $19.20 \%$ nacionales y $80.8 \%$ extranjeros (SITE, 2004 y Llamas, 2009: 266).

Para los turistas nacionales, una de las temporadas vacacionales es Semana Santa. Durante esta época, Puerto Peñasco brinda su hospitalidad a través de diversos eventos culturales que deleitan a todos los vacacionistas, quienes además de disfrutar de la vida nocturna, pueden gozar de las bellezas naturales del lugar: playa, mar, sol y el Gran Desierto de Altar.

Un destino en crecimiento, con un gran potencial humano y natural en la región, ha permitido analizar cómo vincular el desarrollo turístico de Puerto Peñasco con la Reserva de la Biosfera El Pinacate y Gran Desierto de Altar, para articular su potencial al turismo alternativo.

\section{Antecedentes}

\section{Desarrollo sustentable}

El desarrollo genera el bienestar de los individuos, regiones y comunidades, por lo tanto, involucra al medio ambiente:"al tratar de integrar el desarrollo con el medio ambiente, se enfatiza en la característica de lo sustentable del desarrollo" (Urciaga García, 2005: 346).

La preocupación surge en el nivel internacional por los efectos negativos de un desarrollo que no pone límites al crecimiento económico ni al consumo 
de recursos, lo que origina una enorme degradación ambiental,ya percibida en los años setenta y constatada en el estudio que realizó el Club de Roma, donde se revelaba la insostenibilidad, en el largo plazo, de un modelo sustentado en un sobre-consumo de recursos. Estos acontecimientos motivaron la búsqueda de nuevas alternativas de desarrollo en las que estuviera presente la relación dinámica y dialéctica que se establece entre el medio ambiente y el hombre y el medio ambiente sociocultural, representado por los individuos en sociedad.

El antecedente del paradigma del desarrollo sustentable en el ámbito internacional fue la primera "Conferencia Mundial sobre el Medio Humano, que tuvo lugar en Estocolmo (Suecia) en junio de 1972, con representantes de II 3 países, como un antes y un después en la problematización política del tema" (Pierri, 2005: 36). Por primera vez se trataron los temas de política internacional, primer intento de conciliar los objetivos tradicionales del desarrollo con la protección de la naturaleza y los intereses de los países de la comunidad internacional.

El desarrollo sustentable se comienza a construir como idea de futuro modelo a partir del trabajo de expertos de los principales organismos internacionales, como la Organización de las Naciones Unidas (ONU), que realizan una fusión de varias corrientes teóricas relacionadas con el manejo de los recursos naturales, ecología y desarrollo económico.

Un gran avance en esta tarea fue la constitución de la Comisión Mundial sobre el Medio Ambiente y el Desarrollo (CMMAD) en 1983, en la XXXVIII Sesión de la ONU, por resolución de la Asamblea General (Pierri, 2005: 60).

La ONU encomendó a la ex ministro de la Comisión, Gro Harlem Brundtland, realizar una reunión de expertos para dar respuesta a la polémica que inició en la década de los setenta sobre el desarrollo y la posibilidad de crear nuevos modelos alternativos, por ser una idea que venía de parte de ella y el grupo que lideraba.

El tema central del informe es la propuesta, definida de una manera muy general, de un modelo alternativo al que denominaron desarrollo sustentable, partiendo de un criterio ya aceptado de la sustentabilidad en algunos casos como la agricultura en el manejo silvícola y luego en la pesca, lo que puede ser ampliado a un modelo mundial. Este modelo fue definido en el documento titulado Our Common Future (1987) como aquel "que satisface las necesidades de la generación presente sin comprometer la capacidad de las generaciones futuras para satisfacer sus propias necesidades" (Wong González, 2005: I I8). 
El turismo alternativo en la

Reserva de la Biosfera El Pinacate

y Gran Desierto de Altar, Sonora,

México

A partir del Informe Brundtland se han realizado diversos proyectos para la aplicación de políticas públicas que parten de la sustentabilidad, con la finalidad de reducir el impacto de las actividades económicas en los distintos ámbitos geográficos; entre las acciones se encuentran la creación de instituciones para proteger la biodiversidad, así como el establecimiento de una amplia normatividad ambiental y de políticas para frenar el deterioro ambiental.

A raíz de este consenso se empezó a dar una serie de interpretaciones, y en algunas ocasiones surgieron propuestas con orientaciones contradictorias y otras con intereses parciales, por ejemplo las que sólo consideraban la variable ambiental o la social, dejabando parte del fenómeno sin evaluar o analizar.

Se inició en paralelo un cuestionamiento semántico sobre cuál concepto se debería usar: sustentable o sostenible o el uso indistinto de ambos, sustentabilidad y sostenibilidad, que no significan lo mismo, y la confusión radica en la traducción del idioma inglés.

Bifani (1993) sostiene que la expresión inglesa "sustainable development" introduce en su versión castellana un elemento de distinción, ya que en español significa conservar una cosa en su ser o estado, lo cual da idea de un esfuerzo por evitar que una cosa caiga o se deteriore (Bifani citado por Cesar y Arnaíz, 2002:57).

Existe una diversidad de nociones sobre desarrollo sustentable que se relacionan con la concepción económica, la ambiental, la humanista y la turística, entre otras, aunque hay que agregar que el propio concepto y modelo se han ido readecuando a nuevas circunstancias y cambios en el modelo general del capitalismo global. En términos económicos consideran el desarrollo sustentable como "un patrón de transformaciones económicas, sociales y estructurales (desarrollo), que optimizan la economía y otros beneficios sociales disponibles en el presente, sin arriesgar el potencial de beneficios similares en el futuro" (Goodland, I 988:4I).

En el otro extremo se encuentran quienes privilegian la sustentabilidad ecológica, y que generalmente hacen énfasis en la incorporación de las condiciones ecológicas y en la necesidad de rescatar las visiones tradicionales, además de que perciben la naturaleza como un modelo a seguir para diseñar la vida humana.

En mayo de 1990 se elaboró un informe relativo a la conferencia regional de nivel ministerial sobre el seguimiento del informe de la Comisión Mundial sobre el Ambiente y el Desarrollo que avanza en los contenidos del desarrollo sustentable, documento base para la preparación de la Conferencia sobre el Ambiente y el Desarrollo que se llevaría a cabo en Río en 1992 (Boada y Toledo, 2003:24). 
A principios de los noventa, en la Asamblea General de las Naciones Unidas realizada en Nueva York, se aprueba la realización de una Conferencia sobre el Medio Ambiente y el Desarrollo en la ciudad de Río de Janeiro en Brasil, la cual es planeada para junio de 1992. En este escenario se elaboró y aprobó un programa global conocido como Agenda 2I para dar institucionalidad y legitimidad a las políticas del desarrollo sustentable (Left, 2004: I04).

La Agenda $2 \mathrm{I}$ engloba los temas del desarrollo que afectan al medio ambiente, los elementos del desarrollo sostenible y las prácticas para el fortalecimiento de los grupos de la población con objeto de lograr este tipo de desarrollo. La Declaración de Río sobre el Medio Ambiente y el Desarrollo define los derechos sobre el desarrollo con responsabilidad para la búsqueda del desarrollo sustentable de acuerdo a las políticas establecidas, así como el deber de los Estados para el fortalecimiento del desarrollo sustentable. Esta conferencia, conocida como la Cumbre de Río, reunió a las naciones y organizaciones no gubernamentales (ONG) del planeta Tierra, e incorporó planteamientos que implicaban un compromiso con el medio ambiente y el desarrollo, asegurando el desarrollo económico y social. Fueron aprobados diversos documentos, entre los cuales destacan la Declaración de Principios sobre los Bosques, las Convenciones sobre el Cambio Climático, el Tratado sobre la Diversidad Biológica y la Convención sobre la Desertificación.

En septiembre de 2000, como un nuevo avance para lograr un desarrollo sustentable y reducir las asimetrías económicas y sociales, se logró la aprobación de la agenda denominada Metas de Desarrollo del Milenio, con énfasis en las políticas de globalización y en la erradicación de la pobreza y el hambre, y que fue asumida como un compromiso por 199 países. Dos años después se efectúa otra cumbre mundial en Sudáfrica, logrando que se firmen nuevos compromisos sobre los acuerdos de Río que fueron renovados diez años después en la Cumbre Mundial sobre Desarrollo Sustentable, celebrada en Johannesburgo en septiembre de 2002 (Left, 2004: 104).

Los dirigentes mundiales se dieron cita en Nueva York el 25 de septiembre de 2008 en una reunión de alto nivel convocada por el secretario general de la ONU y el presidente de la Asamblea General del mismo organismo, para renovar los compromisos en la consecución de los objetivos de desarrollo del milenio determinados para 2015, establecer planes concretos y adoptar las medidas prácticas necesarias. 
El turismo alternativo en la

Reserva de la Biosfera El Pinacate

y Gran Desierto de Altar, Sonora,

México

Así, se llega al final de la primera década del siglo XXI buscando acuerdos y generando propuestas a fin de avanzar en la aplicación de un verdadero desarrollo sustentable, que sea viable para todos los países del mundo.

\section{Desarrollo sustentable y turismo}

El desarrollo sustentable aplicado al turismo parte del reto de hacer compatible el desarrollo turístico con el medio ambiente en el cual se desarrolla o toma como principal objeto de esta actividad, busca frenar el modelo depredador que se ha desarrollado en este fenómeno heredado del modelo general del capitalismo global.

El Programa $2 \mathrm{I}$, término oficial de la agenda $2 \mathrm{I}$ adoptado por la ONU, está encaminado a acelerar medidas para alcanzar un desarrollo sostenible de los países, al incrementar la riqueza y, a la vez, erradicar la pobreza, logrando la conservación del medio ambiente.

Agenda $2 \mathrm{l}$ es un plan estratégico que comprende aspectos económicos, sociales, políticos, culturales y ambientales para promover el desarrollo sustentable en todos los países de la Tierra con la participación de comunidades $y$ agentes sociales locales.

Uno de sus objetivos es promover actividades como la pesca y el desarrollo del turismo sostenible equilibrado, para incrementar los ingresos, conservando la integridad cultural y del medio ambiente, así como mejorar la infraestructura y los servicios sociales, y reforzar la protección de las áreas ecológicas y el patrimonio natural, para el fortalecimiento de las comunidades locales.

El desarrollo turístico sustentable considera la aspiración de hacer compatible el desarrollo turístico con la naturaleza, teniendo como base la preocupación por el futuro del ser humano, tanto los turistas como la comunidad receptora.

En el reporte ECOMOST, que constituye la investigación europea sobre desarrollo turístico sustentable, se define la sustentabilidad en el turismo como "tratar de mantener un equilibrio que permita al turismo funcionar con rentabilidad, pero no a expensas de los recursos naturales, culturales o ecológicos" (Jiménez Martínez, 2005: 88).

Un modelo interesante que intenta ser sustentable en México es el proyecto de Mazunte, en Santa María Tonameca, Oaxaca, una población que vivía de la explotación de las tortugas marinas, y donde los habitantes, al integrarse a una organización turístico-ecológica y con el apoyo de diversos grupos ambientalista, lograron pasar de la explotación a la protección combinada con el turismo, lo cual ha resultado exitoso. 
En la Conferencia Europea sobre Ciudades y Pueblos Sostenibles celebrada en Aalborg, Dinamarca, en mayo de 1994, firmaron la Carta de Aalborg más de 330 participantes, entre ellos 80 municipios europeos, cuyo objetivo era llegar al consenso sobre la Agenda 21 de alcance local (Boada y Toledo, 2003: 32).

La Segunda Conferencia de Pueblos y Ciudades Sostenibles se llevó a cabo en Lisboa, Portugal, durante octubre de 1996,y allí se informaron y se evaluaron los avances realizados por varios países europeos en torno a la Agenda 21 local. La Conferencia se concluyó con un documento final denominado "De la Carta de Acción", basado en las experiencias expuestas por quienes firmaron la Carta de Aalborg, y pretende recoger y ampliar el compromiso hacia el desarrollo sostenible en el plano local.

La Organización Mundial del Turismo (OMT) ha definido al turismo sostenible como "aquel desarrollo turístico que responde a las necesidades de los turistas actuales y las regiones receptoras y al mismo tiempo protege y fomenta las oportunidades para el futuro" (OMT citado por Quintero,2008:84).

Las directrices van dirigidas a la gestión de todos los recursos para que puedan satisfacer las necesidades económicas, sociales y ambientales, respetando la integridad cultural, los procesos ecológicos, la diversidad biológica y los sistemas que sostienen la vida. Esta conceptualización plantea que un proceso de desarrollo turístico sostenible local debe estar acorde a una propuesta de desarrollo que busque:

- Proporcionar un uso óptimo a los recursos ambientales, elemento fundamental del desarrollo turístico, conforme a los procesos ecológicos y naturales y la biodiversidad biológica

- Respetar la autenticidad sociocultural de las comunidades anfitrionas, conservar sus actividades culturales arquitectónicas y sus valores tradicionales, y contribuir al entendimiento y a la tolerancia intercultural

- Ser económicamente viable a largo plazo, aportando a todos los agentes sociales beneficios socioeconómicos y brindando oportunidades de empleo estable y de obtención de ingresos y servicios sociales a las comunidades anfitrionas, contribuyendo a reducir la pobreza.

Asimismo, la OMT ha celebrado diversas reuniones concernientes a la definición y formulación del desarrollo sostenible para el turismo, dada la grave situación de algunas cuestiones como el cambio climático global, la elevación de 
El turismo alternativo en la

Reserva de la Biosfera El Pinacate

y Gran Desierto de Altar, Sonora,

México

los mares y otras que afectan al turismo (www.world-tourism.org/sustainable/ esp/concepts.htm).

En México, la Secretaría de Turismo en coordinación con la de Medio Ambiente y Recursos Naturales lideran los esfuerzos dirigidos a conformar la Agenda 2l para el Turismo Mexicano, cuyo objetivo es:"Ser un programa que guíe las acciones e instrumentos, para propiciar el Desarrollo Sustentable de la actividad turística, consolidando el bienestar del ser humano, respetando el medio ambiente y optimizando los beneficios económicos y sociales de las comunidades" (Sectur, 2005: 9).

- Dentro de las estrategias de desarrollo turístico, la Agenda 21 considera:

- La implementación de una Agenda local para municipios turísticos

- Un sistema de indicadores de sustentabilidad para el turismo

- La promoción de mejores prácticas ambientales en empresas y destinos

- Un programa de incentivos a la actividad turística sustentable

- Un programa de capacitación de transferencia de tecnología

- El ordenamiento ecológico-turístico del territorio

- El ecoturismo como clave para el turismo en áreas naturales protegidas (ANP)

En 2005 se presentaron en México casos con relativo éxito por parte de los comités locales de Agenda 21 , entre ellos San Miguel de Allende, Cozumel, Riviera Maya, Rosarito y Los Cabos. Hasta este periodo, los municipios que cuentan con la organización de un Comité local de Agenda 21 son: Acapulco, Bahía de Banderas, Cozumel, Ixtapa-Zihuatanejo, Los Cabos, Mazatlán, Puerto Vallarta, Rosarito y otros. Varios más se encuentran en proceso de instalación del Comité de Agenda 2I local, como Cancún, Puerto Peñasco, Riviera Maya y Tijuana. Éste es el paso de la teoría a la realidad, pero aún son hechos aislados y no se vislumbra una política que ponga límites al turismo depredador. En síntesis, el paradigma del desarrollo sustentable aplicado al mundo y específicamente al turismo ha sido reducido a políticas difusas tendientes a evitar la crítica de la sociedad y los organismos de la sociedad civil, sin realizar cambios de fondo como el problema lo exige.

Áreas naturales protegidas

La situación mundial se caracteriza por la creciente crisis ambiental, que es uno de los problemas cruciales para la humanidad. Las prácticas depredadoras del 
hombre han ocasionando severos daños al ambiente, debido a la creciente demanda de recursos naturales y a la contaminación causada por algunos ricos para mejorar su nivel de vida.

A partir de estos acontecimientos, se presenta una gran preocupación en el contexto global, por conservar el ambiente. Las áreas protegidas tienen una tradición cultural y una larga historia. Inglaterra y Estados Unidos fueron los principales promotores en la creación de asociaciones y leyes en defensa de la naturaleza, aunque sus raíces surgen desde el siglo XIX; posteriormente continuaron Francia,Alemania y España. "En Estados Unidos es donde surge la idea de preservar grandes espacios en su estado original, como paisajes y 'santuarios' para la vida animal y vegetal, dejando fuera la presencia humana” (Pierri, 2005: 31).

Con ese propósito se destina en 1864 el valle delYosemite en California; en 1872, la ley estadounidense crea Yellowstone como un parque nacional para el uso y disfrute de la población (Eagles, Mc Cool y Haynes, 2003: 6). Todos los parques nacientes tenían rasgos comunes: surgían por iniciativa de los gobiernos, eran por lo general extensos e integraban entornos relativamente naturales, $y$ estaban a disposición de todo el mundo. Países como Australia, Canadá y Sudáfrica también empezaron a instituir sus áreas protegidas.

A finales del siglo XIX surgieron ideas para crear organismos internacionales dedicados a proteger la naturaleza, pero se vieron frustradas por los dos grandes acontecimientos bélicos mundiales. Concluida la Segunda Guerra Mundial, “y creada la ONU en 1945. Ésta nombró al biólogo británico Julian Huxley presidente de la UNESCO, [...] creándose la Unión Internacional Provisional para la Protección de la Naturaleza en 1947, la que fue formalizada definitivamente en la reunión de la UNESCO de Fontainebleau (París, 1948)" (Pierri, 2005:3 I-32).

De esta manera,"fue fundada en 1948, la Unión Internacional para la Conservación de la Naturaleza (UICN), que es la red más extensa, integrada por estados, agencias gubernamentales y diversos rangos de organizaciones no gubernamentales de conservacionistas asociados en el mundo" (Kelleher, 1999: I).

La UICN se enfocó particularmente en la conservación de la biodiversidad y la administración de hábitats y lugares naturales como punto de partida, "pero reconocer a la vez la importancia de otros objetivos de esas zonas como pueden ser el esparcimiento y el turismo" (Eagles, Mc Cool y Haynes, 2003:6).

La constante preocupación por el creciente deterioro del ambiente de la Tierra llevó a la comunidad internacional a implementar líneas de acción para 
El turismo alternativo en la

Reserva de la Biosfera El Pinacate

y Gran Desierto de Altar, Sonora,

México

lograr áreas naturales protegidas que respondieran a una estrategia de prioridades relativas a la riqueza, fragilidad y extensión de los ecosistemas;"se obtuvo una respuesta por parte de la UNESCO, por medio del programa 'El hombre y la Biosfera' que consistió en el establecimiento de la nueva categoría de protección y manejo denominada reserva de la biosfera" (Murillo Flores y Orozco Alvarado, 2006: 27).

Las reservas de la biosfera son áreas representativas de uno o más ecosistemas no alterados por la acción del ser humano o que no requieran ser restaurados, en las cuales habitan especies representativas de la biodiversidad nacional, incluyendo a las consideradas amenazadas o en peligro de extinción. (www.conanp.gob.mx)

A partir de estos acontecimientos en el contexto global, con la participación de la comunidad científica mexicana se estableció por primera vez en nuestro país el Plan Nacional de Ecología.

Hoy en día, la conservación de la biodiversidad es una de las prioridades en el planeta Tierra. En México, desde las culturas prehispánicas hasta los tiempos actuales se han implementado diversas estrategias para la conservación de las áreas naturales, dirigiéndose principalmente a las áreas naturales protegidas y a la gran variedad de plantas y especies con que cuentan las diversas regiones del país. La importancia concedida a las ANP "se fundamenta por su tamaño y naturalidad, representan fielmente el universo biológico del mundo, con sus estructuras y funciones en desarrollo de genes, especies, poblaciones, comunidades, ecosistemas, paisajes y regiones, así como en los procesos ecológicos esenciales (biogeoquímico, climático, hidrológico y evolutivo, entre otros), que son la base para el uso sustentable de los recursos naturales" (Murillo Flores y Orozco Alvarado, 2006: II).

En México se han realizado esfuerzos para la conservación de las áreas naturales protegidas y las diversas especies representativas de plantas y animales, incluyendo a las que se consideran amenazadas o en peligro de extinción. Las ANP datan de épocas pasadas, "la primera que se decretó en el país fue el Mineral del Chico, Hidalgo, durante el gobierno de Porfirio Díaz, y se hizo copiando el sistema estadounidense puesto en marcha en el siglo XIX, el cual se erigió en paradigma de la conservación en todo el planeta" (Murillo Flores y Orozco Alvarado, 2006: II).

En 1876 se expropia el Desierto de los Leones y para 1917 se convierte en el primer parque nacional del país. A raíz de estos sucesos en la historia de 
México se han ejecutado distintas acciones para lograr la conservación de la biodiversidad y de los recursos naturales, así como frenar el deterioro del medio ambiente.

Actualmente, la Comisión Nacional de Áreas Naturales Protegidas (Conanp) cuenta con un registro de 150 áreas naturales de carácter federal que representan más de 17.8 millones de hectáreas. De acuerdo a su clasificación, existen 34 reservas de la biosfera, 65 parques nacionales, cuatro monumentos naturales, dos áreas de protección de recursos naturales, 26 áreas de protección de flora y fauna, 17 santuarios y dos áreas en proceso de que se les emita el decreto y se definan sus propósitos.

Al noroeste del territorio sonorense se sitúa la Reserva de la Biosfera El Pinacate y Gran Desierto de Altar, la cual se establece por decreto presidencial el 10 de junio de 1993. Con una extensión de 7/4 557 hectáreas, comprende los municipios de General Plutarco Elías Calles, Puerto Peñasco y San Luis Río Colorado; cuenta con ecosistemas representativos de áreas desérticas, vegetación de dunas móviles y estabilizadas, y en ella se encuentra una gran riqueza de fauna silvestre y el cono volcánico.

Las vías de acceso hacia El Pinacate y Gran Desierto de Altar se ubican por la carretera Sonoyta-Puerto Peñasco, en el kilometro 73 y en el 5 I donde se ubica la estación biológica.

El turismo se ha convertido en uno de los sectores fundamentales a partir de la segunda mitad del siglo $x X, y$ continuará creciendo en los próximos años. Con esta expansión se están diversificando los productos y destinos turísticos y está incrementando la demanda de turismo de naturaleza que constituye uno de los principales atractivos.

En las áreas naturales protegidas mexicanas el turismo ha sido considerado como una actividad económica sustentable y susceptible de ser aprovechada en armonía con el medio ambiente y la sociedad. Hoy en día, las tendencias por incorporar al turismo con las ANP son mayores. En este sentido,"la gestión del ANP debe estar acorde con la actual y futura demanda turística. Esto debe significar una oportunidad para coadyuvar al logro de los objetivos de las ANP en el marco del desarrollo sustentable" (Murillo Flores y Orozco Alvarado, 2006: 56).

Es aquí donde se inserta la investigación sobre la Reserva de la Biosfera El Pinacate y Gran Desierto de Altar en la que se realizan gestiones para el 
El turismo alternativo en la

Reserva de la Biosfera El Pinacate

y Gran Desierto de Altar, Sonora,

México

desarrollo del turismo alternativo teniendo en cuenta los objetivos de conservación de las áreas protegidas y buscando minimizar los impactos ambientales y socioculturales, de tal manera que se logre una actividad turística sustentable que a la vez sea una fuente de ingresos tanto para el área protegida como para los pobladores de las localidades que la rodean.

\section{Metodología}

El universo de estudio se circunscribe en Puerto Peñasco, situado en el noroeste del estado de Sonora. Colinda al Norte con Estados Unidos de América y el municipio General Plutarco Elías Calles, al Noroeste con el municipio de San Luis Río Colorado, al Sureste con Caborca, y su límite al Sur es el Golfo de California (véase figura I). Se localiza a 100 kilómetros de la frontera con Estados Unidos (Gobierno Municipal de Puerto Peñasco, 2007: 9).

El acceso principal al municipio es por la Carretera Federal Núm. 8 que enlaza a Puerto Peñasco con Sonoyta y entronca con la Carretera Federal Núm. 2 que conecta al Oeste con Baja California, al Norte con la Carretera 85 de Estados Unidos (US Hwy 85) y al Este con la Carretera Federal Núm. I5, principal vía de comunicación en el estado de Sonora; la Carretera Estatal Núm. 3 une a Puerto Peñasco con Caborca (Plan Municipal 2006-2009).

Según indica la Secretaría de Comunicaciones y Transportes, se realizaron los trabajos de construcción de la Carretera Costera de Sonora que comprende el tramo El Golfo de Santa Clara-Puerto Peñasco, se localiza en la parte noroeste del Estado, en los municipios de San Luis Río Colorado y Puerto Peñasco. La carretera tiene 135 kilómetros de longitud, para alojar dos carriles de circulación de 3.5 metros cada uno, y acotamientos laterales de 2.5 metros cada uno.

Esta carretera es otra alternativa de comunicación rápida, segura y que proporciona facilidades de acceso al mercado para el turismo nacional e internacional de Baja California y el suroeste de Estados Unidos. Las diversas vías de comunicación ofrecen excelentes paisajes del Gran Desierto de Altar donde se puede apreciar la flora y fauna de la región.

El municipio está comunicado tanto con la entidad, el resto del país y sus vecinos estados del sur de la Unión Americana. Puerto Peñasco cuenta con un aeródromo internacional de corto alcance, con una pista de aterrizaje de I 500 metros de longitud. A últimas fechas se han establecido vuelos chárter con la 


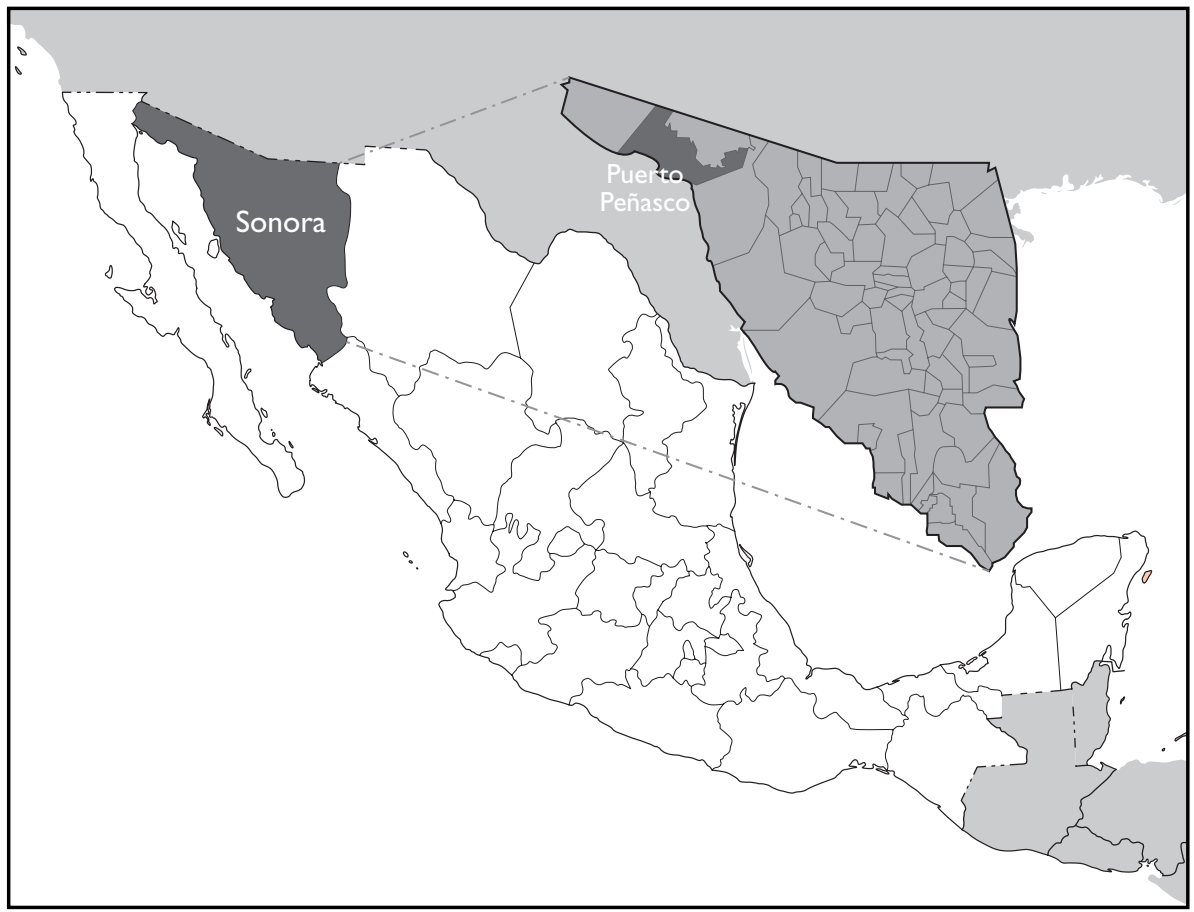

Figura I. Localización de Puerto Peñasco, Sonora, México

ruta Phoenix-Puerto Peñasco, además de recibir vuelos privados que provienen principalmente de los estados de Arizona, Nuevo México y California.

Para iniciar el trabajo de investigación se identificaron las fuentes de información para su recopilación y análisis; se localizaron documentos, información y estudios similares o comparativos sobre el desarrollo de Puerto Peñasco y la actividad turística en los diversos niveles a fin de definir el marco teórico a partir de los estudios teóricos y metodológicos existentes.

La ciencia sociológica nace de enclaves donde no existe un problema específico que podamos diferenciar como algo propio y básico. Entre sus características sobresale el requisito de aplicar el método científico, separándose de reflexiones, especulaciones y saberes recogidos en el pensamiento social,y constituir su propio pensamiento sociológico científico sobre los temas referentes a ese contexto, estableciendo una cadena por la acumulación de aportaciones objetivas contrastables, susceptibles de ser verificadas y basadas en datos y 
El turismo alternativo en la

Reserva de la Biosfera El Pinacate

y Gran Desierto de Altar, Sonora,

México

hechos concretos tomados de la misma realidad social para ser sometida a los requisitos del proceder científico (Martínez Quintana, 2006: 53).

Para el trabajo de campo se combinaron métodos; en el proceso se aplicó la metodología tanto con un enfoque cualitativo como con uno cuantitativo que conllevan elementos de análisis objetivos (Hernández Sampieri et. al, 2003: 4-I4). La investigación se desarrolló en dos etapas: la primera con un enfoque cualitativo, que se llevó a cabo a través de entrevistas de profundidad aplicada a los principales actores de diversos sectores productivos; la segunda, con un enfoque cuantitativo, para recabar datos mediante los instrumentos y obtener datos estadísticos de las distintas actividades del municipio, la región y el estado.

Con base en el tamaño de la población, se definió una cantidad representativa para poblaciones amplias en la investigación social. Se aplicaron 80 encuestas al azar dirigidas a la población local en comercios, plazas, el malecón, avenidas, playas y casas-habitación. Entre las preguntas efectuadas para caracterizar a la población se encuentran sexo, lugar de procedencia y actividad desempeñada. Respecto a turismo y ocio en la sociedad, se consideraron atractivos turísticos que frecuentan, disponibilidad para incorporarse a la actividad turística local, necesidades de capacitación, su preferencia por visitar El Pinacate y Gran Desierto de Altar, y los efectos del turismo en la localidad. Al concluir la aplicación del instrumento se continuó con el procesamiento y graficado de las encuestas empleando el programa Excel.

Resultados

\section{Caracterización de la población}

El Conteo de Población y Vivienda 2005 (INEGI, 2005) indica que Puerto Peñasco tiene 44875 habitantes, $51.96 \%$ del sexo masculino y $48.04 \%$ del sexo femenino. Entre los encuestados en la comunidad se encontró que $69 \%$ son hombres y 3 I \% mujeres. Para el periodo 1995-2005 se presenta una variación positiva de $39.5 \%$ en la población, debido al impulso de la actividad turística, la reactivación de la actividad pesquera y la generación de nuevas empresas de servicios en la localidad.

Como ya se indicó, la mayoría de los habitantes encuestados son hombres, quienes forman parte importante de la fuerza productiva en la comunidad, aun- 
que la participación de la mujer ha sido de gran trascendencia a partir del auge de la industria maquiladora del camarón. Hoy en día trabajan aproximadamente 35 mujeres en área operativa por industria, además de supervisoras y socias. Asimismo, a partir del impulso a la actividad turística la mujer juega un papel relevante ocupando niveles administrativos y operativos en diversas empresas turísticas.

Los datos del trabajo de campo arrojaron que $65 \%$ de los habitantes de Puerto Peñasco son originarios del estado de Sonora, $16 \%$ de Sinaloa, $6 \%$ de Jalisco, $3 \%$ de Chihuahua y I \% de las entidades de Baja California, Guerrero, Michoacán, Nayarit, Oaxaca, Puebla,Veracruz y el Distrito Federal, respectivamente.

Turismo y ocio en la sociedad: una alternativa para el turismo

En el trabajo de campo se encontró que los habitantes encuestados en la localidad visitan con frecuencia diversos atractivos turísticos: $90 \%$ tiene preferencia por pasear en el malecón; $88 \%$ frecuenta las playas, entre ellas la de la Cholla, Las Conchas y Playa Bonita; I $4 \%$ ha visitado los monumentos históricos del puerto; II \% ha ido a los esteros; $10 \%$ asiste a los parques de la localidad; $5 \%$ ha visitado el muelle y $2 \%$ el Centro de Estudios de Desiertos y Océanos (CEDO) y la zona hotelera.

Los encuestados manifiestan su interés por incorporarse al sector servicios: $77 \%$ está de acuerdo en formar parte de la actividad turística local; I $2 \%$ se encuentra laborando actualmente en el ramo turístico; $8 \%$ no está de acuerdo en participar como prestador de servicios turísticos y $3 \%$ no contestó. Esto refleja el gran interés de la mayoría de los residentes por integrarse en alguna de las empresas para desempeñarse dentro del sector turismo.

Los habitantes consideran que es necesario recibir capacitación para incorporase a la actividad turística: $73 \%$ de los interesados en participar en el sector turismo piensa que requiere capacitación, mientras que $14 \%$ creee que no la necesita y $13 \%$ no respondió. La mayoría de los residentes de la localidad muestra un gran interés por recibir capacitación para integrarse a la actividad turística.

La reserva de la biosfera está conformada por valores geológicos, culturales, biológicos y paisajísticos; cada uno de ellos constituye un atractivo turístico excepcional. De los entrevistados, 56\% manifiesta conocer El Pinacate, $43 \%$ no ha visitado la Reserva, mientras que I \% no contestó; aproximadamente la mitad de los trabajadores entrevistados en la localidad conoce la reserva de 
la biosfera. Es importante destacar que entre la población existe un considerable mercado potencial para promover el turismo alternativo teniendo como opción la Reserva de la Biosfera El Pinacate y Gran Desierto de Altar.

La zona del cono volcánico es uno de los atractivos turísticos naturales frecuentado por el turismo nacional y extranjero. Los registros de la Dirección General de la Reserva de la Biosfera El Pinacate y Gran Desierto de Altar indican que, para 1997, la afluencia de visitantes fue de 3177 personas, de las cuales $54.33 \%$ son nacionales y provienen de diversos estados de la república, sobre todo de Sonora, Baja California, Distrito Federal, Estado de México, Jalisco, Sinaloa, Chihuahua, Colima y Nuevo León.

De los encuestados, $23 \%$ expresa que ha transitado la zona una o dos ocasiones para conocer el cono volcánico, I5\% ha visitado la Reserva de tres a cinco veces, $10 \%$ ha asistido con una periodicidad de seis a diez veces, $6 \%$ ha frecuentado el Pinacate entre 15 y 20 ocasiones, $15 \%$ ha presenciado las bellezas naturales de El Pinacate y Gran Desierto de Altar de 30 a 50 veces, y $44 \%$ no ha visitado la Reserva nunca.

Para el nuevo siglo, frecuentaron la zona volcánica 5628 visitantes, de los cuales 3994 eran nacionales (70.97\% del total de visitantes) y I 634 eran extranjeros, provenientes de Estados Unidos y países europeos $(29.03 \%$ del total), disminuyendo ligeramente la cantidad de visitantes respecto al año anterior. Para julio de 2007, el total de asistentes fue de 10256 , de las cuales $84.9 \%$ fueron turistas nacionales y $15.1 \%$ extranjeros.

La investigación de campo arrojó que, de los habitantes entrevistados que han visitado la Reserva de la Biosfera El Pinacate y Gran Desierto de Altar, 43\% es originario de Sonora; $13 \%$ proviene de Sinaloa ,Jalisco, Michoacán, Nayarit, Puebla y el Distrito Federal; en tanto los que no han visitado la Reserva de la Biosfera proceden del estado de Sonora (21\%) y de Sinaloa, Baja California, Chihuahua, Guerrero, Jalisco, Oaxaca y Veracruz (2l \%); mientras que I \% no contestó. De los 3400 residentes que visitaron la Reserva, alrededor de la mitad de los habitantes entrevistados recorrieron las bellezas naturales de El Pinacate.

El total de vehículos registrados fueron 2 I 2 I de los que I 658 (78.2\%) son nacionales y $(21.8 \%)$ son extranjeros.

En el trabajo de campo se detectó que cinco por ciento considera necesario que se proporcione información sobre la Reserva de la Biosfera El Pinacate y Gran Desierto de Altar y otros atractivos turísticos; recomienda 
Cuadro I.Visita de turistas a la Reserva de la Biosfera El Pinacate y Gran Desierto DE Altar

\begin{tabular}{|c|c|c|c|c|c|}
\hline Años & $\begin{array}{c}\text { Total de } \\
\text { visitantes }\end{array}$ & $\begin{array}{l}\text { Visitantes } \\
\text { nacionales }\end{array}$ & (\%) & $\begin{array}{l}\text { Visitantes } \\
\text { extranjeros }\end{array}$ & (\%) \\
\hline 2000 & 5.628 & 3.994 & 70.97 & 1.634 & 29.03 \\
\hline 2005 & 8.141 & 6.303 & 77.42 & 1.838 & 22.58 \\
\hline 2007 & 10.256 & 8.133 & 84.9 & 1.450 & 15.1 \\
\hline
\end{tabular}

Fuente: Conanp. Reporte de Visitaciones de 2000, 2005 y 2007.

que se establezcan módulos que brinden información turística sobre los diversos atractivos turísticos locales y regionales, los hoteles y la gama de atractivos turísticos que pueden ser visitados en el destino turístico.

Los pobladores muestran un gran interés por incorporarse a la actividad turística en la localidad. El trabajo de campo señaló que todos los pobladores encuestados creen que requieren capacitación en una o más áreas del conocimiento para integrarse a la actividad turística: $83 \%$ considera el idioma inglés como prioritario; $43 \%$ contempla como indispensable tener conocimientos sobre la información turística local; $8 \%$ observa que es necesaria la cultura general; $6 \%$ requiere conocimientos en computación; $4 \%$ reflexiona sobre la importancia de la cultura turística; un mismo porcentaje necesita conocimientos específicos sobre atención al cliente; I I \% solicita capacitación en gastronomía, recursos humanos, relaciones públicas, electricidad y plomería; mientras que $6 \%$ no respondió.

Al igual que otros destinos turísticos en desarrollo del país, surgen nuevas necesidades y una diversidad de problemas. Respecto a los efectos socioculturales más comunes que enfrentan los turistas encuestados durante su estancia en el puerto, $8 \%$ apunta la falta de seguridad ante el cuerpo policiaco; $4 \%$ señala la inseguridad, manifestando que hay robos y peleas; $13 \%$ opina que se requiere mayor seguridad en las playas y en la localidad, así como más vigilancia en los eventos que se organizan, sugiriendo que se cuente con un cuerpo de salvavidas en las playas; en tanto $55 \%$ exige que las autoridades combatan la corrupción, la discriminación, el vandalismo, la drogadicción y la delincuencia, y piden más seguridad y vigilancia en la ciudad. En cambio, I $3 \%$ argumenta que el destino turístico está bien. 
El turismo alternativo en la

Reserva de la Biosfera El Pinacate

y Gran Desierto de Altar, Sonora,

México

Con relación a los impactos ambientales detectados por los residentes, éstos piensan que el turismo contamina el medio ambiente, tira basura y contamina las playas y el muelle, mientras que $9 \%$ enfatiza que está depredando los recursos naturales. De los turistas que visitaron el destino turístico durante Semana Santa, una minoría enfatiza en la contaminación ambiental, ocasionada por fogatas en las playas y exceso de ruido por las noches; de la misma manera, afirman que urge más limpieza y botes para la basura en distintos puntos de la ciudad y en el malecón.

Discusión

Décadas atrás Puerto Peñasco era un sitio aislado del estado, incluso de México y del mundo; era desconocido y se encontraba fuera de los circuitos mundiales del turismo, pero esta situación ha comenzado a cambiar. El Mar de Cortés es uno de esos lugares globales de los cuales mucha gente del mundo tiene conocimiento, lo cual genera una tendencia a conocerlo, otorgando un plus muy elevado a estos destinos turísticos emergentes.

El turismo de sol y playa favorece a Puerto Peñasco, pero éste debe brindar un producto turístico integral capaz de atraer al turismo por la convivencia humanística de la población y por sus bellezas naturales. El puerto tiene buenas oportunidades de crecer, con su interesante mezcla de turismo nacional y de los vecinos fronterizos.

La sustentabilidad es algo complejo y no se circunscribe, como unos pensaban antes, a la cuestión ambiental, ya que el eje es eminentemente social; la pobreza, el desarrollo desigual y las asimetrías en el acceso a los servicios son limitaciones que hacen imposible alcanzar esta meta.

A pesar de los esfuerzos realizados sobre sustentabilidad, continúan los problemas ambientales. El turismo no debe ser un problema actual ni tampoco del futuro; el turismo bien planeado optimiza el destino turístico para que el desarrollo sea sustentable, el turismo es un promotor de conservación ambiental.

El desarrollo turístico en la localidad provoca diversos impactos ambientales a lo largo de todo el litoral: las construcciones hoteleras y marinas, los campos de golf y el crecimiento poblacional, afectan el equilibrio de los ecosistemas; aunado a ello, la contaminación ocasionada por deshechos y basura y el deterioro de los recursos naturales, entre otros son problemas ecológicos, han afectado el polo de desarrollo turístico. Ante ello, actualmente se han desarrollado acciones tendientes a minimizar los efectos del turismo a través 
de la implementación del Comité del Programa 2I, así como de programas de limpieza y plantas tratadoras de agua.

\section{Conclusiones}

El desarrollo turístico que ha tenido Puerto Peñasco en los últimos años ha llamado la atención de miles de visitantes, ocasionando el turismo de masas, situación que permite considerar como opción la diversificación de las actividades, promoviendo el turismo alternativo en uno de sus atractivos turísticos más importantes: la Reserva de la Biosfera El Pinacate y Gran Desierto de Altar, donde se observa un mercado potencial importante, ya que la mayoría de los turistas nacionales y extranjeros que visitan el puerto desconocen la zona volcánica.

El desarrollo turístico de Puerto Peñasco tendrá como primera opción de diversificación al turismo alternativo en El Pinacate y Gran Desierto de Altar, que cuenta con valores históricos, culturales, naturales y geológicos dignos de apreciarse en el enclave del desierto, creando productos turísticos para un segmento de mercado más especializado.

El turismo genera dos diferentes flujos de personas, que son los turistas y los inmigrantes económicos; estos dos grupos tienen distintos destinos: para uno está el lujo de los hoteles y todos los servicios, mientras que el otro busca interactuar con la naturaleza y obtener los mínimos servicios, lo cual se caracteriza por minimizar los impactos negativos en el medio ambiente. La tendencia para este último grupo es el turismo alternativo.

\section{Recomendaciones}

Puerto Peñasco es un destino turístico joven reconocido internacionalmente, que cuenta con un gran potencial turístico. Por ende, es necesario que exista una planeación eficaz en coordinación con las autoridades locales, la participación de los habitantes y el personal directivo de la reserva de la biosfera, para promover uno de los atractivos turísticos naturales donde se puede apreciar la zona volcánica del Gran Desierto de Altar.

El estado ha rodeado a esta importante región de grandes reservas de la biosfera, con el apoyo de institutos especializados y personal calificado. El Pinacate y Gran Desierto de Altar, entre ellas la de la zona volcánica es un 
El turismo alternativo en la

Reserva de la Biosfera El Pinacate

y Gran Desierto de Altar, Sonora,

México

atractivo turístico susceptible de ser aprovechado de manera consciente y racional, por lo que se debe realizar una planeación eficaz aplicando medidas de protección y conservación eficiente del área natural protegida, mediante la puesta en práctica de proyectos productivos que contribuyan al desarrollo en la localidad para elevar la calidad de vida de los habitantes.

La sustentabilidad es compleja y no se limita, como se pensaba antes, a la cuestión ambiental, ya que el eje es eminentemente social. La implementación de proyectos productivos con un enfoque de preservación y conservación hacia el área natural protegida, contribuirá a la generación de empleos para los pobladores locales.

\section{FUENTES CONSULTADAS}

Boada, M.y V.M.Toledo (2003). El planeta, nuestro cuerpo: la ecología, el ambientalismo y la crisis de la modernidad. México: Fondo de Cultura Económica.

Cesar, D. A y Arnaiz, S.M. (2002). Globalización, Turismo y Sustentabilidad, Universidad de Guadalajara, Puerto Vallarta Jalisco.

Eagles, Paul F.J., Stephen F. McCool y Christopher D. Haynes (2003). Turismo sostenible en áreas protegidas. Directrices de planificación y gestión. Madrid: Organización Mundial del Turismo/Programa de las Naciones Unidas para el Medio Ambiente/Unión Mundial para la Naturaleza.

Foladori, G. y N. Pierri (coords.) (2005). ¿Sustentabilidad? Desacuerdos sobre el desarrollo sustentable. México: Universidad Autónoma de Zacatecas/ Editorial Porrúa.

Gobierno Municipal de Puerto Peñasco (2007). Plan Municipal de Desarrollo 2007-2009. Puerto Peñasco:XIX H.Ayuntamiento de Puerto Peñasco, Sonora.

Hernández Sampieri, R., et al. (2003). Metodología de la investigación. México: Trillas.

INEGI (2005). Conteo de Población y Vivienda 2005. Aguascalientes: Instituto Nacional de Estadística, Geografía e Informática. Disponible en: http:// www.inegi.org.mx/est/contenidos/proyectos/ccpv/cpv2005/Default. aspx [2008, 5 de abril].

Jiménez Martínez, A. de J. (2005). Desarrollo turístico y sustentabilidad: el caso de México. México: Miguel Ángel Porrúa. 
Kellerher, G. (ed. y coord.) (1999). Guidelines for Marine Protected Areas. Gland y Cambridge: Comisión Mundial de Áreas Protegidas, Unión Mundial para la Naturaleza.

Left, E. (2004). Racionalidad ambiental: la reapropiación social de la naturaleza. México: Siglo XXI Editores.

Llamas, P.M.R. (2009). Desarrollo y emergencia del turismo en Puerto Peñasco, Sonora, Puerto Vallarta, Jalisco.

Martínez Quintana, V. (2006). Ocio y turismo en la sociedad actual. Los viajes, el tiempo libre y el entretenimiento en el mundo globalizado. Madrid: McGraw-Hill/Interamericana de España.

Murillo Flores, F.J.y J. Orozco Alvarado (2006). El turismo alternativo en las áreas naturales protegidas. México: Centro Universitario de la Costa, Universidad de Guadalajara.

Pierri, N. (2005). "Historia del concepto de desarrollo sustentable”, en G. Foladori y N. Pierri (coords.). ¿Sustentabilidad? Desacuerdos sobre el desarrollo sustentable. México: Universidad Autónoma de Zacatecas/ Editorial Porrúa, 27-8I.

Reserva de la Biosfera El Pinacate y Gran Desierto de Altar y Conanp (2007). Reporte anual de visitación. Puerto Peñasco: Reserva de la Biosfera El Pinacate y Gran Desierto de Altar/Comisión Nacional de Áreas Naturales Protegidas.

Sectur (2005). El turismo en México. México: Dirección General de Información y Análisis, Secretaría de Turismo.

Sistema de Información Turística del Estado (SITE) (2004). Programa de Desarrollo de la Industria Turística 2004-2009. Hermosillo: Gobierno del Estado de Sonora.

Urciaga García, J. (2005). "Indicadores de desarrollo regional sustentable de Baja California Sur”, en P.A.Torres Lima (coord.). Desarrollo regional y sustentabilidad en México. Sonora y México: Universidad Autónoma Metropolitana/El Colegio de Sonora.

Wong González, P. (2005). "Fundamentos teórico-conceptuales del desarrollo regional sustentable", en P.A.Torres Lima (coord.). Desarrollo regional y sustentabilidad en México. Sonora y México: Universidad Autónoma Metropolitana/El Colegio de Sonora, I I I-I35. 